\title{
Fine particulate matter associated with monsoonal effect and the responses of biomass fire hotspots in the tropical environment
}

\author{
M. F. Khan et al.
}

Correspondence to: M. F. Khan (mdfiroz.khan@gmail.com)

The copyright of individual parts of the supplement might differ from the CC-BY 3.0 licence. 
$\square$ BS $\square$ BS Disp $\square$ Disp - Bsse Run Error Estimation Concentration Summary
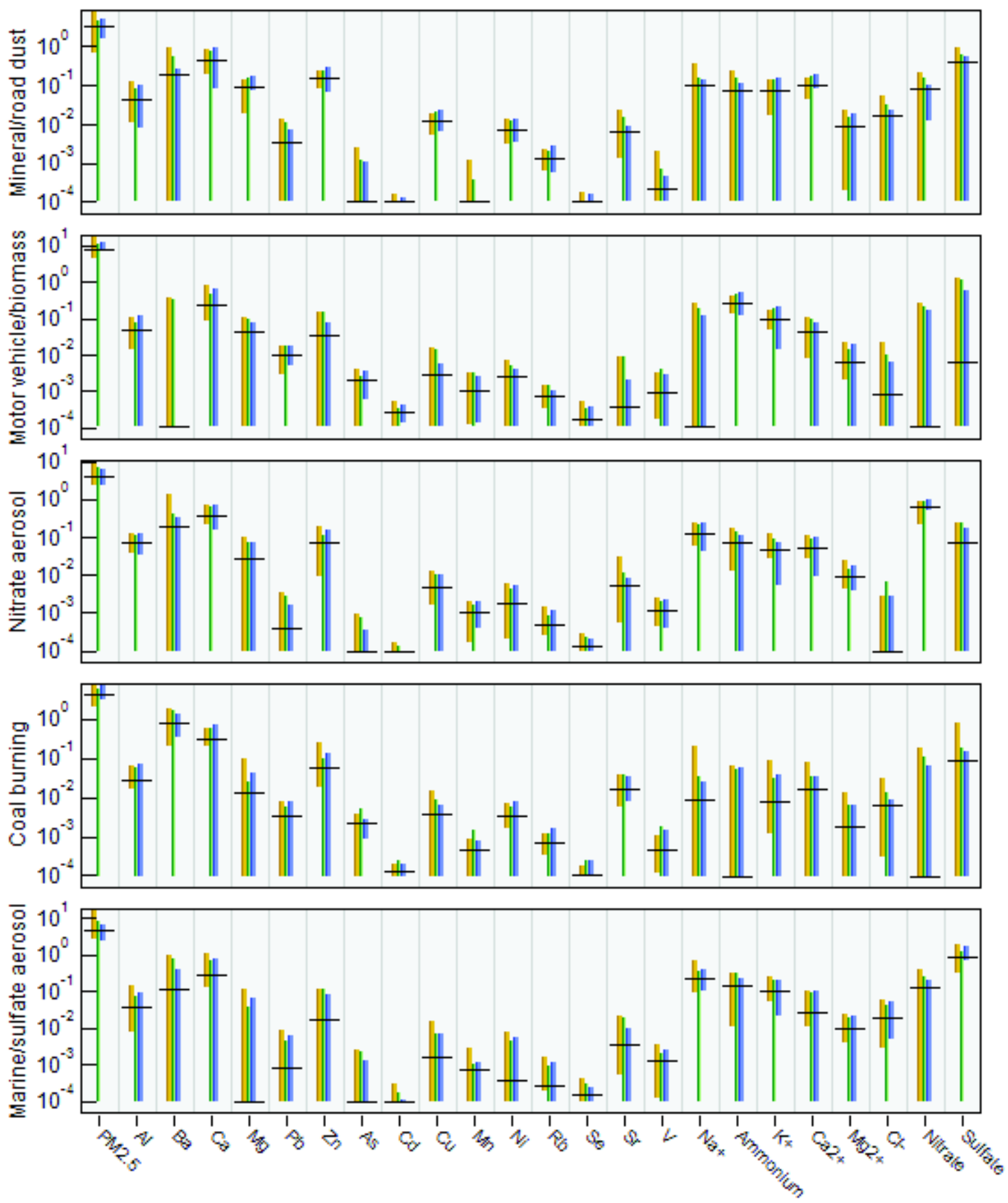

Supplementary Figure 1 The base run and error estimation of the concentration by BS, BS Disp and Disp 